\title{
Full STEAM ahead, but who has the map for integration? - A PRISMA systematic review on the incorporation of interdisciplinary learning into schools
}

\author{
Daniel White ${ }^{1}$ and Seamus Delaney ${ }^{2}$ \\ ${ }^{1}$ Asquith Girls High School, Australia \\ 2 School of Education, Deakin University, Australia
}

Science, Technology, Engineering and Mathematics or "STEM" focused pedagogy has been influenced changes in education for decades. Responding to the need for interdisciplinary skilled workforces, the STEM approach has been revised firstly to reflect the incorporation of Arts, (STEAM) and, more recently, to place stronger emphasis on cross-disciplinary connections. However, there is little empirical evidence to drive the development of a practical model for classroom implementation. This systematic review aims to consolidate existing empirical evidence on the incorporation of interdisciplinary learning via a STEM/STEAM approach in high-school environments using a PRISMA review scaffolding. The review identified ninety-nine articles that addressed interdisciplinary learning. However, the majority of them were excluded due to the lack of empirical evidence for such improvements, resulting in only eleven studies being included in the final synthesis. This suggests that more research is required prior to wide-scale implementation within high school education systems. Of those that met the selection criteria, the overarching theme was that improved outcomes were best achieved via either a real-world project-based or problem-based learning pedagogy with the use of community and industry support. However, due to the low number of studies found to fit the criteria, it is recommended that further research is conducted to provide greater empirical evidence to support this finding.

Keywords: high school, interdisciplinary, transdisciplinary, multidisciplinary, PRISMA systematic review, STEAM, STEM

\author{
ARTICLE DETAILS \\ LUMAT Special Issue \\ Vol 9 No 2 (2021), 9-32 \\ Received 22 August 2020 \\ Accepted 23 February 2021 \\ Published 18 March 2021 \\ Pages: 24 \\ References: 64 \\ Correspondence: \\ s.delaney@deakin.edu.au \\ https://doi.org/10.31129/ \\ LUMAT.9.2.1387
}

\section{Introduction}

The phrase "STEM education" is used to describe a focus on the teaching of, and the learning within Science, Technology, Engineering, and Mathematics (STEM) fields (Gonzalez \& Kuenzi, 2012). A focus on STEM rose to prominence in the US educational arena in response to the ongoing low performance of American students in mathematics and science on international assessments, such as TIMSS and PISA (Breiner, Harkness, Johnson, \& Koheler, 2012; Gonzalez \& Kuenzi, 2012; Klein, 2008; Marinova \& McGrath, 2004; McClam \& Flores-Scott, 2012; Roehrig, Moore, Wang, \& Park, 2012; Savage, 2012; Wang, Moore, Roehrig, \& Park, 2011). Many other countries faced similar challenges and placed an importance on STEM linked subjects within their educational framework (Corlu, Capraro, \& Capraro, 2014; Scholz, Lang, Wiek, 
Walter, \& Stauffacher, 2006; Yakman \& Lee, 2012). In Australia, STEM education emphasis was implemented as a means of developing a "21 ${ }^{\text {st }}$ century orientated" workforce (Price Waterhouse Coopers Australia, 2018; Taylor, 2016) as it became apparent that employment, irrespective of the field or level, required knowledge and capabilities within the disciplines covered by STEM-related disciplines (Al Salami, Makela, and Miranda, 2017; Breiner et al., 2012; Corlu et al., 2014) and there was a need for STEM literacy and capabilities within the population (Scholz et al., 2006). This emphasis has continued within both educational research and its practical application in the classroom. For example, Science \& Education recently published an entire issue addressing STEM education research and its application (Erduran, 2020).

Originally, STEM education could be considered as a focus on teaching and learning within the separate and distinct disciplines that make up the acronym (Science, Technology, Engineering, Mathematics) with little or no overlap between the educational experience within. Recently in response to pressure on the curriculum developers to ensure that education should reflect the real-world, STEM education has been transformed into a multidisciplinary educational approach with a stronger emphasis on integrating the learning across these disciplines. Integrated STEM education could be considered as an approach that incorporated content of two or more STEM domains for the purpose of enhancing the learning outcomes of the student. Proponents of this curricular change argue that such a teaching platform reflects more real-world parallels (Breiner et al., 2012; Taylor, 2016; Wang et al., 2011). Creating disciplinary boundaries between the components creates an inefficient instruction model for students and limits their capacity to transfer their classroom learning into the real world. Furthermore, some Academics believe that the problem-solving approaches developed within the integrated STEM paradigm are needed to create innovative thinkers with interdisciplinary capabilities (Brown, 2012; Corlu et al., 2014; Madden et al., 2013). Such thinkers are required to address the complex issues facing the world today, such as social and economic inequality and climate change (Corlu et al., 2014; McClam \& Flores-Scott, 2012; Savage, 2012; Spelt, Biemans, Tobi, Luning, \& Mulder, 2009; Webber \& Miller, 2016).

Terms such as interdisciplinary, transdisciplinary and integrated are often used to describe integrated STEM educational approach (Keane \& Keane, 2016; Klein, 1990; McClam \& Flores-Scott, 2012; Taylor, 2016). It is worth noting from the outset of this review, that this field of educational innovation has been fraught with a plethora of different terminology and conceptualisations, many of which either 
strongly overlap or describe similar phenomena (Brown, 2012; Wang et al., 2011). As such, what one researcher may refer to as Transdisciplinary, another will label it Interdisciplinary. Table 1 highlights some of the key components of the different terminology. While there is some variation in the literature in the use of these terms, these definitions were selected as being as being representative of the generally accepted conceptualisation of the terms and highlight the clear demarcation between the concepts that they encompass.

Table 1. Different interpretations of the thinking arising from integrated STEM/STEAM pedagogy

\begin{tabular}{|c|c|c|}
\hline Forms of Thinking & Conceptualisation & References \\
\hline $\begin{array}{l}\text { Multidisciplinary } \\
\text { thinking }\end{array}$ & $\begin{array}{l}\text { Combinations of thinking arising from } \\
\text { learning in different disciplines but with } \\
\text { distinct and clear lines of demarcation } \\
\text { between them. In this regard, } \\
\text { Multidisciplinary can be thought of as an } \\
\text { additive. }\end{array}$ & $\begin{array}{l}\text { Marinova and McGrath, 2004; } \\
\text { McClam and Flores-Scott, 2012; } \\
\text { Park and Son, 2010; Spelt et al., } \\
2009 .\end{array}$ \\
\hline $\begin{array}{l}\text { Interdisciplinary } \\
\text { thinking }\end{array}$ & $\begin{array}{l}\text { The ability to synergise knowledge from } \\
\text { multiple disciplines in a way that leads to } \\
\text { an understanding or outcome that would } \\
\text { not have been possible from drawing } \\
\text { information from a single discipline. } \\
\text { Interdisciplinary programs focus on the } \\
\text { collaboration and interaction between the } \\
\text { disciplinaries. In this regard, } \\
\text { interdisciplinarity can be thought of as } \\
\text { integrative. }\end{array}$ & $\begin{array}{l}\text { Klein, 1990; Marinova and } \\
\text { McGrath, 2004; Spelt et al., } \\
\text { 2009; McClam and Flores-Scott, } \\
\text { 2012; Park and Son, 2010; Wang } \\
\text { et al., } 2011 .\end{array}$ \\
\hline $\begin{array}{l}\text { Transdisciplinary } \\
\text { thinking }\end{array}$ & $\begin{array}{l}\text { Transdisciplinary focuses on the outcome } \\
\text { where the boundaries between the } \\
\text { disciplines are not relevant and creation of } \\
\text { new knowledge is the focus. The goal of } \\
\text { transdisciplinary learning is to foster } \\
\text { holistic global understanding and } \\
\text { appreciation for the unity of knowledge. } \\
\text { In this regard, Transdisciplinary can be } \\
\text { thought of as inclusive. }\end{array}$ & $\begin{array}{l}\text { Marinova and McGrath, 2004; } \\
\text { McClam and Flores-Scott, 2012; } \\
\text { Park and Son, 2010; Wang et al., } \\
2011 .\end{array}$ \\
\hline
\end{tabular}


In even more recent times, this 'real-world' push has resulted in a tendency for Arts to be incorporated into the traditional STEM program, moving from STEM to STEAM to better achieve this goal of developing complex problem solvers. Table 2 gives a brief overview of some of the key conceptualisations of this approach. The justification for this is that the development of innovative and creative problem solvers requires the "creativity" component that a STEAM-based curriculum would provide compared to a strictly STEM curriculum (Madden et al., 2013) and that the integration of Arts subjects (i.e. liberal arts, social studies, physical and fine arts and music) within STEM aids in the development of higher-order abilities to deal positively and productively with 21st century global challenges (Taylor, 2016; Madden et al., 2013). While the capacity to develop creativity within STEM through the addition of Arts is a contested issue (Martins Gomes \& McCauley, 2021, Le Grande, 2018, Root-Bernstein, 2001), proponents of the inclusion argue that the traditional STEM components focus on convergent skills, so the inclusion of Arts will allow for divergent skills acquisition as well (Land, 2013). In addition, findings by Rinne, Gregory, Yarmolinskaya and Hardiman (2011) suggested that utilising components of the Arts pedagogy may result in improved long-term content retention in students. Similar to this, Inoa, Weltske and Tabone (2014) found that students within Artintegrated classes showed improved mathematics scores.

With such strong educational policy change, support, investment, literature and research into integrated STEM/STEAM education, it is surprising then that there is not stronger evidence of improvements in the areas that lead to an emphasis on STEM education in the first place. For example, recent results would suggest that the STEM deficiency is still occurring (Klein, 2008; Land, 2013; Marinova \& McGrath, 2004; Stubbs \& Myers, 2016; Wang et al., 2011) and there has not been the expected improvements in STEM education outcomes (Gonzalez \& Kuenzi, 2012; Sanders, 2009). Gonzalez \& Kuenzi (2012) for example identify ongoing concerns with academic achievement gaps, teacher quality and the ability to meet the labor market demands for STEM labor. The final concern is of particular note as this was, in part, the aspect of the education programs that fuelled the reorientation towards STEM in the first place. 
Table 2. A brief description of the key conceptualisations of STEM education

\section{Acronym/ \\ Termin-ology \\ MST/SMT \\ S-T-E-M. \\ Description and explanation \\ A very early incarnation with a focus on Mathematics, Science and Technology. \\ A stronger emphasis on the development of skills in the fields of Science, Technology, Engineering and Mathematics without a focus or emphasis on the interaction between the different fields.}

Integrated

STEM (or

iSTEM)

eSTEM

SteM, sTEm

etc

\section{$E$ \\ stM.}

STEAM

STEAM by

design

STREAM

STEM education with a focus on the interaction between the disciplines or a subgroup of those disciplines, alternatively between "STEM" subjects and other disciplines such as those within the Humanities realm of education (i.e. History).

STEM education with a strong digital and technology focus.

A range of approaches where there is either an unequal focus on the different components, for example "SteM", which denotes a strong emphasis on Science and Mathematics with some reference to Technology and Engineering.

Integration of components from other disciplines into pre-existing courses, such as including Science/Technology/Mathematics components within an Engineering course.

A more recent incarnation of the pedagogy that promotes the incorporation of Arts within STEM programs. Arts has been argued to provide a platform for greater creativity and divergent thinking.

STEAM education that occurs within a "Place base project" paradigm.

Critical reading and/or writing, combined with STEAM.

\section{Example(s) of usage}

Kelley, 2010; Thomas and Williams, 2009.

Breiner et al., 2012; Moher, Liberati, Tetzlaff and Altman, 2009; Sanders, 2015; Taylor, 2016; Wang et al., 2011.

Breiner et al., 2012; Brown, 2012; Corlu et al., 2014; Kelley, 2010; Moher et al., 2009;

Taylor, 2016; Wang et al., 2011.

Jaeger, 2015.

Dugger, 2010.

Dugger, 2010.

Al Salami et al., 2017; Land, 2013; Madden et al., 2013; Yakman and Lee, 2012.

Keane and Keane, 2016.

Root-Bernstein and Root-Bernstein, 2011. 
One possibility for this is the lack of empirical evidence-supported guidelines for educators on how to mesh STEAM, particularly in its more recent inter/transdisciplinary incarnation, with existing pedagogies. It could be argued, therefore, that this lack of academic rigour is a contributing factor in why efforts towards true integrated teaching have not always been successful. Supporting this, Hasni, Lenoir and Alessandra (2015) claimed that the field of integrated STEM often makes broad claims but has little evidence to back up this and also argued for more research to be conducted. Drawing from classroom teachers' experiences, Wang et. al. (2011) highlighted that creating an integrated educational approach is a monumental challenge. In practical terms, teachers who are used to teaching in a traditional silo approach may not be prepared for the holistic integrated approach of integrated STEM (El-Deghaidy, Mansour, Alzaghibi, \& Alhammad, 2017; Hasni et al., 2015; Stubbs \& Myers, 2016; Wells, 2011).

Teachers are not the only individuals within the integrated STEM paradigm to experience difficulties with integrated thinking. Students as well have been shown to have problems learning across discipline and synthesising information from multiple fields (Spelt et al., 2009; Webber \& Miller, 2016). Furthermore, while many educational institutes may claim their STEM/STEAM approach is integrated, there is little evidence of such integration occurring (Papacosta, 2007). For example, Breiner et al. (2012) and Hasni et al. (2015) both point out that, while several STEM programs did bring apparent positive benefits to the classrooms, they involve little integration and real-world demonstration of cross-disciplinary work.

In Brown (2012), a study with the explicit focus of exploring the research base of STEM education, of the total 60 articles examined, almost half of the papers were categorised as non-research derived. In addition, none of the articles reviewed provided a suggested means of implementation of STEM education. As concluded by Brown (2012, p. 10) there is a drastic lack of "large studies analysing student performance and engagement in K-12 classrooms". Roehrig et al. (2012) and Savage (2012) both emphasised that the lack of guidelines and models on how to implement such a program is one of the greatest challenges facing K-12 STEM education.

That is not to say there have not been attempts at developing a model for implementation. For example, STEM/STEAM has been discussed in terms of childcentred learning, democratically based classrooms and open-ended fluid curriculum (Rufo, 2013) to name a few. However, there is little data to support these claims and most of the literature rests on theoretical parallels and "assumed" common grounds. 
Hasni et al. (2015) and Papacosta (2007) proposed a definition of integrated STEM, which excluded all pedagogical approaches that did not utilise technological/engineering design-based pedagogy without empirical evidence to support such removal. Campbell (2011) provides an in-depth list of basic concepts that need to be addressed in terms of implementation but little practical instruction on how this is to occur or evidence for why these concepts are key to the success of STEAM implementation. In Klein (1990), an article describing the attributes of a STEM school, there is a strong emphasis on the use of design processes, problemsolving and cognitive modelling, however like above there is little evidence to support this as a valid approach to incorporating STEM. Sanders (2009) argues for the use of purposeful design and inquiry and while it fits well within their description of integrated STEM education, they provide little evidence beyond anecdotal stories. Similarly, Hasni et al. (2015), Kasza and Slater (2017) and Henriksen (2014) rely significantly on individual stories and not extensive evidence-based conclusions. Both Sanders (2009) and Yakman and Lee (2012) proposed that STEM/STEAM sits well within the concept of Constructivism and Cognitive Science, however Yakman and Lee (2012) also links it with several other different educational theories. Neither show evidence for why one theory is more relevant than another outside of their own interpretation of what STEM/STEAM means. Webber and Miller (2016) claimed that their framework for the learning theories and pedagogies would lead to reaching the desired learning outcomes. While they too provided a model to describe potential conceptual frameworks, drawing from situated cognition theory, little empirical data was included. While such an analysis of the state of affairs in educational research may seem overly critical, the purpose is not to dismiss the pioneering efforts of these researchers but simply to clarify that although potential paths have been identified, it is now time for the development of strong evidence-based practices.

It is the aim of this systematic review to consolidate what evidence there is regarding the implementation of STEM in its most recent incarnationinterdisciplinary STEAM and its derivatives, to inform future research. The purpose of this study, therefore, is to explore the successful implementation of this educational platform within the high-school arena via evidence-based reports of improved learning in the students. The closest studies to attempt a similar objective have been Brown (2012) and Spelt et al. (2009). Table 3 summarises the ways in which this review will build upon the findings of Brown (2012). In addition, this review will also complement the Spelt et al. (2009) review within this field, that focused on what sub 
skills need to be developed and what are the typical conditions, by providing empirical support for the models that allow such learning to take place. This study will also provide a similar analysis of the state of educational affairs in terms of research within the secondary or high-school system (as Spelt et al. (2009) focused on higher or tertiary education).

Table 3. Review extensions from Brown (2012)

\begin{tabular}{|c|c|}
\hline Included approach & Achieved by \\
\hline $\begin{array}{l}\text { Refining the focus on empirical } \\
\text { evidence-based reports, an area } \\
\text { identified as lacking in the previous } \\
\text { analysis. }\end{array}$ & $\begin{array}{l}\text { Inclusion of an exclusion criteria directly related to } \\
\text { this aspect of research (EC2). }\end{array}$ \\
\hline $\begin{array}{l}\text { Expanding the search to include a } \\
\text { broader range of journals. }\end{array}$ & $\begin{array}{l}\text { Use of online databases, compared to the peer } \\
\text { identified journal selection of Brown (2012) which } \\
\text { resulted in } 8 \text { journals being selected. This also seemed } \\
\text { appropriate considering the greater focus on } \\
\text { transdisciplinary learning and the STEM/STEAM } \\
\text { paradigm. }\end{array}$ \\
\hline $\begin{array}{l}\text { A rigorous framework for literature } \\
\text { identification. }\end{array}$ & $\begin{array}{l}\text { The PRISMA scaffolding was selected to bring it in line } \\
\text { with other systematic reviews (Moher et al., 2009). }\end{array}$ \\
\hline $\begin{array}{l}\text { Compensation for the automated } \\
\text { component of the review (database } \\
\text { analysis) that may have caused key } \\
\text { articles that use varied terminology } \\
\text { to describe similar educational } \\
\text { concepts being missed. }\end{array}$ & Use of more inclusive search terms. \\
\hline
\end{tabular}

It should be noted that Spelt et al. (2009) distinguished between interdisciplinary (being integrative) and multidisciplinary (being additive). While the differentiation between the terms may be valid, a review of the literature into the evolution of STEM to STEAM and towards interdisciplinary learning would suggest that such a distinction has not been stringently implemented, nor wholeheartedly accepted by educational research. A similar finding was reported by Venville, Sheffield, Rennie and Wallace (2008). Therefore, a number of terms that have been used for similar learning experiences.

Following Spelt et al. (2009) as a template and traditional systematic review protocols, this review will be conducted via a PRISMA directed systematic search within the relevant literature databases, followed by a critical analysis and synthesis 
of the relevant material identified (Spelt et al., 2009). Although the PRISMA scaffolding was originally developed for health science meta-analysis and systematic reviews, it is also applicable for systematic review-based research in other fields (Moher et al., 2009).

\subsection{Research Questions}

This systematic review aims to answer the following research questions:

1. What empirical evidence exists that an interdisciplinary learning platform allows for greater learning outcomes for high-school students?

2. What pedagogies are supported by empirical evidence for the successful implementation (as identified by the achievement of greater learning outcomes discussed in Research question 1) of an interdisciplinary learning platform?

Research question 1 was formulated to address the issue that a large component of the support for interdisciplinary learning has been derived from assumed benefits of such a pedagogical approach. As discussed in the review above, these improved learning can be quite broad-ranging and the Authors did not want to limit the review by imposing constraints on what these learning outcomes were appropriate. Therefore, the validity of benefit was not considered only that such achievement of such benefit was supported by empirical evidence. Research question 2 was formulated to address the issue of a lack of a methodology by which interdisciplinary learning can be achieved in the classroom. These questions along with the appreciation for the varied lexicon identified dictated the eligibility criteria of articles included in this review and informed the critical appraisal of their value regarding this review.

\section{Methodology}

The format for conducting this systematic review follows the steps outlined by Benitti (2012) and the requirements of a PRISMA systematic review (Moher et al., 2009). The key components of the systematic review and how they are reflected in this specific study are:

- Identification of need;

- Development of review protocol;

- Review of the preliminary search; 
- Identification and selection of relevant research; and

- Data synthesis and Discussion.

\subsection{Identification of need}

A review of the literature, which was described above, on the evolution of STEM/STEAM into an interdisciplinary learning platform, identified an apparent scarcity of articles providing an evidence-based methodology for the implementation of such a pedagogy. While there have been several proposed theoretical substrates for interdisciplinary learning, they have provided little practical instruction and evidence to support these instructions for the successful implementation, and thus educators are often without a means of identifying the most relevant methodology for use in their classroom (Kelley \& Knowles, 2016; Taylor, 2016; Roehrig et al., 2012; Spelt et al., 2009). In response to this, Yee-King, Grierson and D'Inverno (2017) and Kelley and Knowles (2016) both argue for more evidence on how best to integrate the learning, the learning scaffolding needed, as well as the instruction design appropriate for integrated learning.

\subsection{Development of a review protocol}

Following the protocol of Spelt et al. (2009), the international online bibliographic databases that were utilised are listed below. The list includes those identified by Spelt et al. (2009), as well as Scopus. In addition, since ERIC was accessed via the metadatabase search engine (PROQUEST), a range of other databases were searched concurrently. These databases were accessed via an online university platform. The included databases were:

1. Educational Resources Information Centre (ERIC);

2. the Science Citation Index Expanded (SCI-EXPANDED);

3. the Social Sciences Citation Index (SSCI);

4. the Arts and Humanities Citation Index (AandHCI);

5. the Conference Proceedings Citation Index- Science (CPCI-S);

6. Conference Proceedings Citation Index- Social Science and Humanities (CPCI-SSH);

7. Book Citation Index- Science (BKCI-S);

8. Book Citation Index- Social Sciences and Humanities (BKCI-SSH);

9. Emerging Sources Citation Index (ESCI); 


\section{Current Chemical Reactions (CCR-EXPANDED); \\ 11. Scopus}

The databases were searched concurrently via the PROQUEST meta-database search engine facility. Searches were restricted to peer-reviewed articles, written in English, and published between 1990 and 15/08/2018, the end date of the data collection period for this systematic review.

In contrast to the protocol of the Spelt et al. (2009) study, the chosen search strategy in this study allowed for the search words to appear anywhere within the text. While this may have led to a larger net being cast in terms of the preliminary database results, the expected small number of returns justified the broader range being used to ensure all potentially relevant material was identified.

With the Search word (SW) the use of the OR command was to account for the varied labels that the relevant concept may fall under. The use of the "?" wild card and * truncation were to account for the varied spelling and uses of the different terms, for example, interdisciplinary and inter-disciplinary and integrating and integrative. If the use of either has somehow resulted in the inclusion of a Search word that did not fit with the underlying definition being explored, it was removed. However, this issue did not arise in the search conducted. Further clarity on the use of wild cards and truncation can be found on the proquest website.

- SW1. Inter?disciplinary OR Multi?disciplinary OR Trans?disciplinary OR Cross?disciplinary

When determining the search words for this systematic review, the Spelt et al. (2009) definition of an interdisciplinary learning experience was drawn upon to inform the selection. Spelt et al. (2009) pointed out that within interdisciplinary learning there is greater emphasis on students having the capacity not to just understand a single field of learning but to draw from multiple perspectives and integrate them into their studies. From this conceptualisation, they defined the interdisciplinary thinking learning experience as "the capacity to integrate knowledge of two or more disciplines to produce a cognitive advancement in ways that would have been impossible or unlikely through single disciplinary means" (page 365). However, a review of the literature would suggest that while this definition may be valid, the terminology has not been broadly accepted. Whether correctly or incorrectly, numerous authors appear to interpret similar learning experiences as described above as interdisciplinary, multidisciplinary, transdisciplinary and cross- 
disciplinary. Therefore, to adhere to this definition, and ensure the broadest possible coverage within this review, additional terminology had to be included.

- SW2. Integrat*

It was noted that a key component of relevant definitions used by Spelt et al. (2009) and others for this form of learning is the integration of understanding across disciplines (i.e. "the capacity to integrate knowledge of two or more disciplines" (Spelt et al. 2009, p. 365). Therefore, a reference to integration of knowledge was included in this search.

- SW3. Secondary OR High?School OR 7-12 OR Middle?School;

- SW4. Educat*

Within recent literature, there has been a strong emphasis on interdisciplinary skill development within the tertiary education field and many resources are available within the primary education field, however there does appear to be a disproportionate lack of research within the secondary education field. Furthermore, how to implement, the capability of and potential benefits of interdisciplinary learning within high schools have been active areas of debate in educational research (Leonardo, 2004, Mergendoller, Maxwell, \& Bellisimo, 2000, Schoenfeld, 2004, Spelt et al., 2009). Therefore, the systematic review required not just the presence of education but also a derivative of secondary or high-school education.

The aim of this review is to inform educators and educational researchers within the high-school arena. However, the review does draw from international sources and as such the delineation between primary and secondary (or high school) is not always comparable. This is particularly relevant in terms of "middle schools" which can range, depending on their locality, from Grades 6-8. Therefore, because of the varied "cut -off" for what is considered "middle school" this was also included in our SW. Subsequent screening removed those that did not constitute a comparable school year to that of a government High-school in Australia. This was achieved by comparing the grades of a middle year and the origin of the study. However, doing so should not detract from the international applicability of the findings of the systematic review. This was done simply to provide comparability across what could be considered a secondary or high school sector globally.

Before searching the literature, the following inclusion/Exclusion criteria were formulated: 
- IC1. Selected publication was required to be relevant to the questions driving the systematic review, meaning that the publication should examine teaching and learning within the interdisciplinary framework as described above and provide evidence-based support for statements made within;

- IC2. Each publication was required to be peer-reviewed;

- IC3. The publication was written in English;

- IC4. The time span of the literature search was limited to 1990-2018 to provide the broadest overview of the research.

Three criteria for exclusion (EC) articles were also identified:

- EC1. Focuses on learning that does not meet the definition of interdisciplinary learning as described by Spelt et al. (2009). Of note here is multidisciplinary learning that involved the presentation of multiple perspectives without integration;

- EC2. Article does not provide an assessment of student learning which highlights an improvement in student learning outcomes compared to traditional pedagogical methods. If an article presented only theoretical conceptualizations, then it was excluded;

- EC3. The article was considered out of context, addressing an area not relevant to the research objectives.

While the comparable assessments required EC2 may be considered difficult to obtain, i.e. comparison of a "silo" based learning experience with that of an interdisciplinary one, there are several different methods that can be utilised to achieve this. These include the use of "content" specific to disciplines covered in both approaches, external assessments such as state-wide assessments, and ongoing participation in the STEM fields.

The IC and EC were implemented in the preliminary screening process. This involved examination of the title, abstract and keywords to ensure the selected articles fitted within the research focus of the study. Where a decision could not be made, or some ambiguity remained on whether the article was a valid selection, the article was included as it was deemed the full-text screening stage would clarify whether it should be included or not. When an abstract was not included in the text, the introduction was examined. 


\section{Review of the preliminary search}

The systematic review was undertaken on 20/7/2018-20/01/2021. It is worth noting that the clear majority of articles were identified via the ERIC database, while most of the other selected databases yield no articles. Figure 1 shows the breakdown of the review and subsequent screening process via the PRISMA flow chart (Moher et al., 2009).

A total of 428 articles were identified based on this preliminary search (442 articles were identified by the PROQUEST database via ERIC search, which automatically excluded 14 articles as duplicates). Two articles were also identified within the Scopus database search. Three articles had been identified previously in the prior-conducted literature review; however, these articles were then excluded during the removal of duplicates, having also been identified in the ERIC search. There were no other duplicates identified other than the ones previously noted by the ERIC/PROQUEST database.
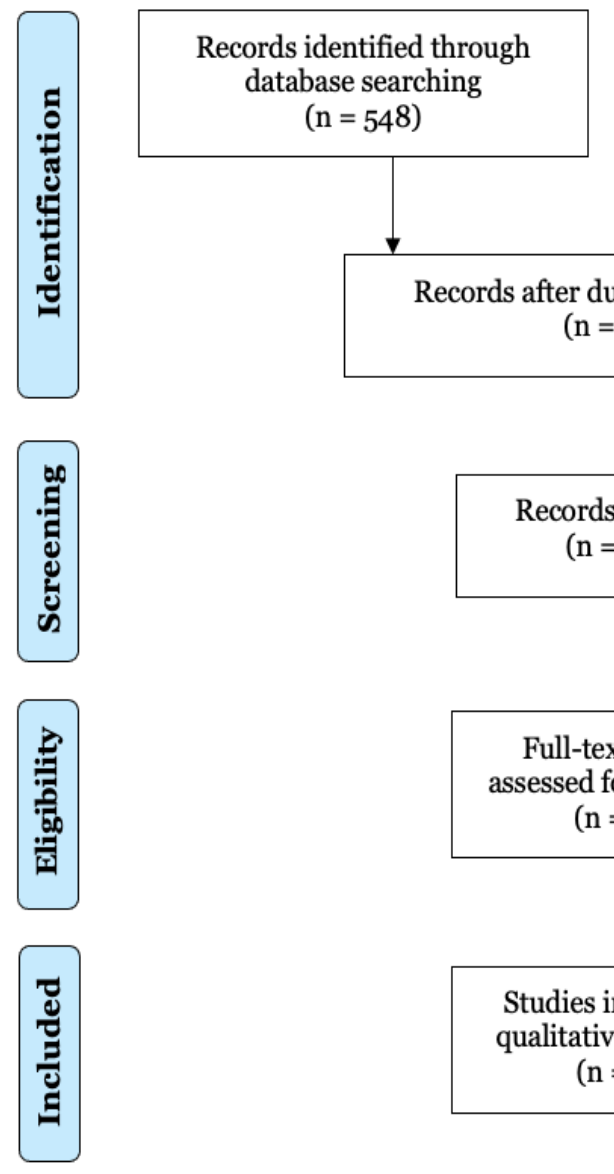

Additional records identified through other sources $(\mathrm{n}=548)$ $(\mathrm{n}=3)$

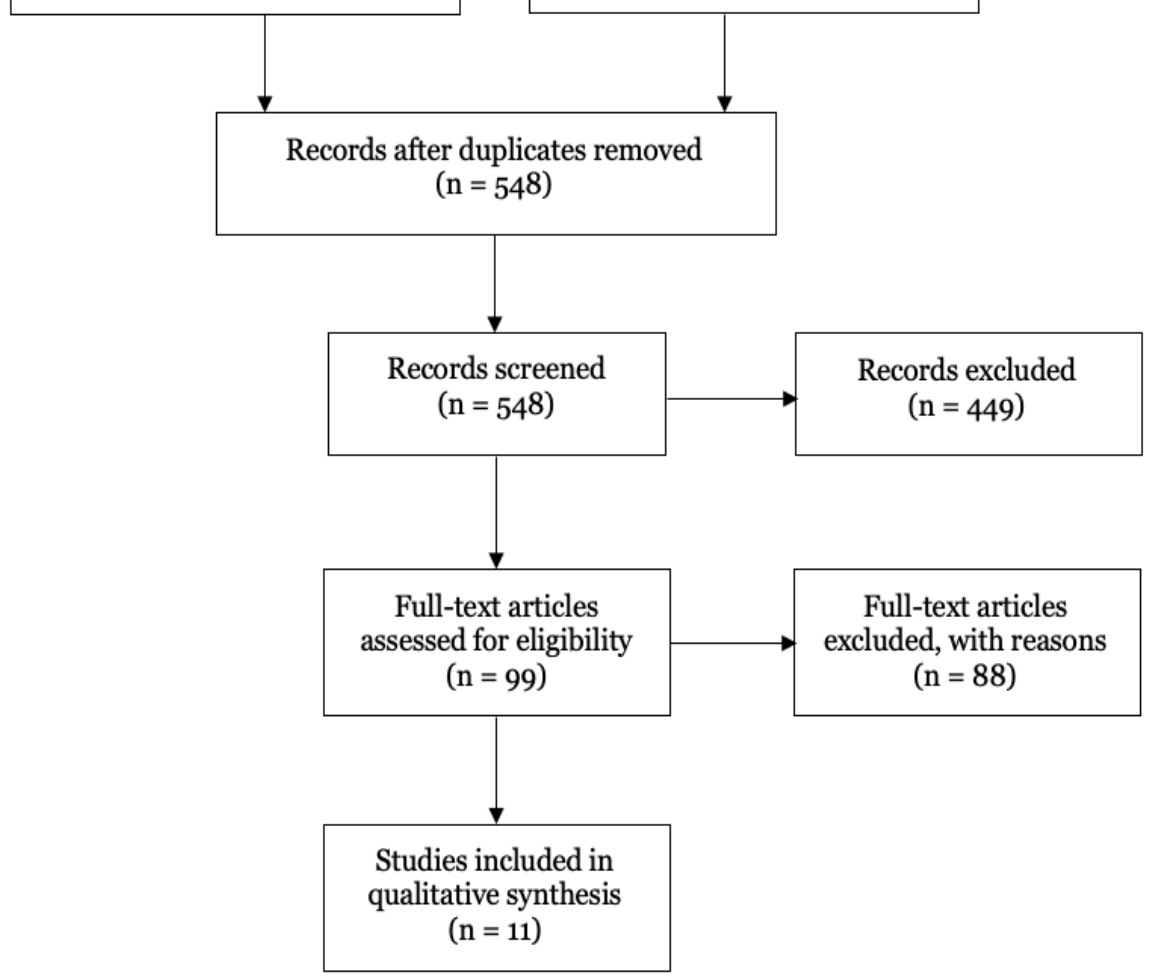

Figure 1. Modified PRISMA Flow Diagram (Moher et al., 2009) 


\section{Identification and selection of relevant research (Screening)}

Upon preliminary screening of the original 548 articles identified, only 99 articles were found to fit the inclusion and exclusion criteria. All these articles, except 2 preidentified articles, were identified within the ERIC/PROQUEST search. For each of these articles, the full text was examined, with regard once more to the EC and IC. The selection or removal of articles and the reason for is summarised in Table 4. It should be noted that an article only had to meet one of the exclusion criteria to be removed and only the first EC identified is listed, so it is possible that some articles would have been excluded under several criteria.

Table 4. Identification and selection of relevant research (Exclusion criteria)

\begin{tabular}{ll}
\hline Exclusion criteria & $\begin{array}{l}\text { No. of articles } \\
\text { removed }\end{array}$ \\
\hline $\begin{array}{l}\text { EC1: Focuses on learning that does not meet the definition of } \\
\text { interdisciplinary learning as described by Spelt et al. (2009), of } \\
\text { note here is multidisciplinary learning involving the presentation } \\
\text { of multiple perspectives with integration }\end{array}$ & 6 \\
$\begin{array}{l}\text { EC2: Article does not provide an assessment of student learning } \\
\text { which highlights an improvement in student academic outcomes }\end{array}$ & 56 \\
$\begin{array}{l}\text { compared to traditional pedagogical methods. If an article } \\
\text { presented only theoretical conceptualisation, then it was } \\
\text { excluded }\end{array}$ & 26 \\
$\begin{array}{l}\text { EC3: The article was considered out of context, addressing an } \\
\text { area of not relevant to the research objectives }\end{array}$ & 28 \\
Total articles excluded & 11 \\
\hline Total articles included & 88 \\
\hline
\end{tabular}

During the full-text screening of each of these articles, 88 articles were removed based on the EC. Consequently, the total number of articles to inform the data synthesis and discussion was eleven. It was worth noting that the majority of the excluded articles were due to a lack of direct comparison of assessment supporting the academic benefits of interdisciplinary learning. While they often provided evidence of interdisciplinary lessons, they either did not provide evidence of learning assessment, or some merely remarked on improvements but did not provide a comparison. Alternatively, they would show there was an improvement after the implementation but with no comparison to traditional educational methods, and 
consequently, it was not clear that the use of the interdisciplinary learning paradigm represented a distinct improvement over the traditional paradigms. As this was the criticism about the state of the field that inspired this study, it is not surprising that there were so few studies that fit this criterion. In addition, it has been suggested that it may be difficult to assess interdisciplinary learning as most existing assessment models focus on the content of a single discipline and therefore do not lend themselves readily to direct comparison (Honey, Pearson, \& Schweingruber, 2014).

The second-largest number of articles excluded were due to EC 3, which addresses the need for the article to have a focus on the specific area of interest for this review. While many articles excluded due to this criterion were within the educational realm of interdisciplinary learning, they often focused on teacher perceptions or the capability of the material.

\section{Data synthesis and discussion}

Eleven articles were as such identified as being relevant to the systematic review research questions and fitting the EC and IC. Each of these eleven articles is outlined in detail in Table 5.

\subsection{What empirical evidence exists that an interdisciplinary learning platform allows for greater learning outcomes for high-school students?}

The overarching theme identified from the relevant eleven articles was that implementing a curricular change that encouraged interdisciplinary learning (or a derivative) resulted in not only higher academic success (compared to student learning within traditional silo style disciplinary education) but also enhanced motivation for learning and problem solving and capacity for complex understanding. This could be considered as evidence for some of the broad claims made by proponents of this pedagogical approach. One interesting finding was that of Yaki et al. (2019) which suggested the use of integrated STEM teaching resulted in improved student outcomes irrespective of the students' ability in science. 
Table 5. Identified relevant articles for data synthesis

\begin{tabular}{|c|c|c|}
\hline No & Article & Description \\
\hline 1. & $\begin{array}{l}\text { Anderson } \\
(2010)\end{array}$ & $\begin{array}{l}\text { Project-based learning, collaborative } \\
\text { work with community and other } \\
\text { students within the automotive } \\
\text { program. Students participated in a } \\
\text { blended curriculum of core } \\
\text { academic and content specific to the } \\
\text { career field. }\end{array}$ \\
\hline 2. & $\begin{array}{l}\text { Inoa et al. } \\
(2014)\end{array}$ & $\begin{array}{l}274 \text { Year } 6 \text { and } 7 \text { students } \\
\text { participated in culturally situated } \\
\text { learning, utilising multi-modal and } \\
\text { trans-mediated strategies. A multi- } \\
\text { stage cluster randomised design was } \\
\text { used to evaluate infusing process } \\
\text { drama into a traditional language } \\
\text { arts curriculum. }\end{array}$ \\
\hline
\end{tabular}

Student outcome

The program has resulted in the school being awarded numerous awards in the state, and a national skills USA competition.

3. Vahey et al. Seventh grade students participated (2012) in a working-with-data project. This consisted of enhancing data literacy through an integrated curriculum of social studies, mathematics, science and English.

4. Ferrero (2006) Centred on a student-centred instructional model focusing on a combination of test preparation, traditional content teaching, and collaboratively developed thematic projects.

Students in the integrated classes outperformed the control (373 students) in both maths and language arts.

The students within the program showed higher skills in data literacy and core discipline-based content compared to control groups.

Students from grades 9-12 within the program showed both improvements and increased participation in the ACT's EXPLORE test, a readiness assessment test, which is part of a program to measure skills development through high school. $10^{\text {th }}$ and $11^{\text {th }}$ grade improvements exceeded predicted growth by 71 percent.

5. Schuchardt and Schunn (2016)

Year 9 and 10 students were taught using integrated STEM pedagogy and compared to students taught using traditional methods.

The students showed improved complex mathematical problem-solving skills and understanding of mathematically modelling processes.

6. Hendry, Hays, Students in grades 9-12 participated Challinor and in project-based learning via Lynch (2017) multidisciplinary projects.

State-wide standardised exit exams showed improvements compared to previous years and other schools with above state average scores in all subjects.

The results showed that students attempted and completed more advanced relevant courses in high-school and collaborative learning within a "Scientific village" paradigm with teachers, STEM professionals and 33 
high-school students on 10 projects. The students were matched to a control group and later tested on interest in and academic success in mathematics and science.

$8 \quad$ Stryf et al. (2019)

$9 \quad$ Huri \& Karpudewan (2019)

Yaki et al. (2019)

11

\section{Condon \&} Wichowsky (2018)
Observational comparisons on grade 9 Mathematics, Physics and Integrated STEM classes.

Integrated STEM lab activities were utilised to improve understanding of electrolysis. Pre- and Post-test analysis and interviews were utilised to test effectiveness of Integrated STEM as a learning platform.

Grade 11 students were either taught a genetics module via an Integrated STEM or traditional pedagogy.

Grade 7 and 8 Students were either taught an integrated STEM/civic science instructions program (STEMhero) or traditional and expressed desires to explore STEM related careers.

Students in Integrated STEM classes showed higher levels of engagement compared to more traditional classes.

Integrated STEM-lab activities explained $33.6 \%$ of the improvements in understanding of Electrolysis. Interviews supported this finding.

Students taught using Integrated STEM exhibited significantly higher improvements in terms of a comparison of Pre- and Post-test data collected via a 40- multiple choice examination.

Students in the STEMhero curriculum showed increased engagement in Science, maths and civics and desire to continue with maths and science.

\subsection{What pedagogies are supported by empirical evidence for the successful implementation of an interdisciplinary learning platform?}

Across the eleven studies reported here, there were a number of themes that consolidate into three key methodological aspects that form an evidence-informed protocol for the implementation of interdisciplinary learning in the high-school education sector.

Firstly, all the studies utilised either a project- or problem-based learning platform. Project-based learning, and to a lesser extent problem-based learning (Schucardt \& Schunn 2015), is considered an approach that provides students with an opportunity to "learn by doing" (Anderson, 2010; Greenes et al. 2011; Hendry et al., 2017) such as completing a lab activity on electrolysis to improve the understanding of the processes involved (Huri and Karpudewan, 2019). As both names suggest, while having their own distinct features, they centred around complex, often multi-stepped 
tasks, with strong student-centred involvement and provides opportunities for authentic learning and experiences (Anderson, 2010; Barron et al., 1998; Savery, 2015; Struyf et al., 2019; Thomas, 2000). It should be noted that one study, Condon and Wichowsky (2019) identified their approach as inquiry-based learning; however, the description of the implementation overlaps many of the aspects discussed in problem and project based. Secondly, these projects or problems were aligned with real-world aspects (Anderson, 2010; Condon \& Wichowsky, 2019; Hendry et al. 2017). This gave the students some context to the content they were learning and potentially led to the improved attitude towards educational experiences described (Ferrero 2006; Greenes et al. 2011). As quoted by one student "I feel like I'm getting a life skill, something I can use outside of any test" (Ferrero 2006, p. 8). In addition, several of the studies identified improvements in key indicators of student attitude, such as completion, attendance and interest in pursuing STEM-related careers. Considering that the decline in STEM-related workforce and population STEM literacy and capabilities were the concerns that prompted the original emphasis on STEM, such a finding is particularly noteworthy. Thirdly, many of the studies emphasised the use of collaboration and community involvement. For example, Greenes et al. (2011) relied heavily on the use of STEM professionals within their scientific 'villages'. Beyond simply increasing the pool of professional knowledge available to the students (Anderson, 2010), this was also found to provide exposure to STEM careers for the students as well as providing data and resources for the projects (Anderson, 2010). Furthermore, utilising the services of such professionals provided the students with exposure to individuals who have already achieved interdisciplinary thinking- a skill that the literature suggests may need refinement as well in the teaching community, who have been trained to work within distinct silo style disciplines (El-Deghaidy et al., 2017; Hasni et al., 2015; Stubbs \& Myers, 2016; Wells, 2011).

However, it is important to emphasise that while 548 articles were identified as addressing interdisciplinary learning, and 99 passed the EC and IC, albeit on the basis of reading the abstract, it was only eleven articles that provided empirical evidence of greater learning outcomes by the students. This would suggest that while student centred project and problem-based learning platforms are an excellent starting point for refining the methodology for an implementation of interdisciplinary learning, there is still a strong need for additional research into the impact on students.

One interesting finding from this systematic review was that many of the studies documented utilised either pre-existing standardised testing or assessments 
developed for a silo-based education system. While even within this paradigm the use of interdisciplinary pedagogy did still show a marked improvement, it does also leave the potential for other benefits unexplored. For example, one of the main critiques of teaching using a traditional "disciplines as silo" style is that it leaves students unprepared for dealing with the "real world" where disciplinary boundaries are less distinct. In comparison, one of the key benefits of interdisciplinary learning was that students were able to make connections between these disciplines when solving problems or developing projects. While discussed, this was rarely comparatively assessed within the studies identified above. Hendry et al. (2017) did identify this discrepancy and discussed some of the options available to address it. Of course, while creating a fair assessment for identifying links between disciplines to compare the outcomes of silo and interdisciplinary education may be difficult, it is worth noting that this and other benefits that an interdisciplinary approach could conceivably achieve may not have been identified in this systematic review.

\section{Conclusion}

The findings of this systematic review support the proposition that the implementation of STEM/STEAM as a platform for interdisciplinary learning does result in higher results in assessed learning outcomes (RQ1) such as greater results in comparable testing, awards and participation in relevant academic pursuits. In addition, such a platform can potentially enhance a range of other outcomes not measured by traditional means. These include greater alignment of teaching and learning to real-world contexts, increased student collaboration, as well as opportunities for community involvement and interaction with professionals employed in STEM-related careers who are more likely to be interdisciplinary minded. The common educational threads for the successful implementation (RQ2) the use of project/problem-based learning and community collaboration and involvement.

In summary, whilst research into the appropriate guidelines for implementation is still in its infancy and further rigorous studies similar to the eleven identified are required, this preliminary research points towards a strong reliance on project or problem-based learning pedagogy with the use of community and collaboration both between students and the greater community. 


\section{References}

Al Salami, M. K., Makela, C. J., \& de Miranda, M. A. (2017). Assessing changes in teachers' attitudes toward interdisciplinary STEM teaching. International Journal of Technology and Design Education, 27(1), 63-88.

Anderson, J. (2010). Interdisciplinary project-based learning leads to success. Tech Directions, 7O(4), 20.

Barron, B. J., Schwartz, D. L., Vye, N. J., Moore, A., Petrosino, A., Zech, L., \& Bransford, J. D. (1998). Doing with understanding: Lessons from research on problem-and project-based learning. Journal of the learning sciences, 7(3-4), 271-311.

Benitti, F. B. V. (2012). Exploring the educational potential of robotics in schools: A systematic review. Computers \& Education, 58(3), 978-988.

Breiner, J. M., Harkness, S. S., Johnson, C. C., \& Koehler, C. M. (2012). What is STEM? A discussion about conceptions of STEM in education and partnerships. School Science and Mathematics, 112(1), 3-11.

Brown, J. (2012). The current status of STEM education research. Journal of STEM Education: Innovations and Research, 13(5), 7.

Campbell, A. (2011). Avenues to Inspiration: Integrating the Life and Work of Nature Artists Into Middle School Science. Science Scope, 35(2), 24.

Condon, M., \& Wichowsky, A. (2018). Developing citizen-scientists: Effects of an inquiry-based science curriculum on STEM and civic engagement. The Elementary School Journal, 119(2), 196-222.

Corlu, M. S., Capraro, R. M., \& Capraro, M. M. (2014). Introducing STEM education: implications for educating our teachers for the age of innovation, Egitim ve Bilim, 39(171).

Dugger, W. E. (2010). Evolution of STEM in the United States', 6th Biennial International Conference on Technology Education Research in Australia. Retrieved from http://www. iteea. org/Resources/PressRoom/AustraliaPaper. pdf.

El-Deghaidy, H., Mansour, N., Alzaghibi, M., \& Alhammad, K. (2017). Context of STEM integration in schools: Views from in-service science teachers. EURASIA Journal of Mathematics Science and Technology Education 13, 1-26.

Erduran, S (Ed.) (2020). Nature of STEM [Special issue]. Science \& Education, 29(4).

Ferrero, D. J. (2006). Having it all. Educational Leadership, 63(8), 8-14.

Gonzalez, H. B. \& Kuenzi, J. J. (2012). Science, technology, engineering, and mathematics (STEM) education: A primer, Congressional Research Service, Library of Congress. Retrieved from http://www.stemedcoalition.org/wp-content/uploads/2010/05/STEMEducation-Primer.pdf.

Greenes, C., Wolfe, S., Weight, S., Cavanagh, M., \& Zehring, J. (2011). Prime the pipeline project (P3): Putting knowledge to work. Contemporary Issues in Technology and Teacher Education, 11(1), 21-46.

Hasni, A., Lenoir, Y., \& Alessandra, F. (2015). Mandated Interdisciplinarity in Secondary School: The Case of Science, Technology, and Mathematics Teachers in Quebec. Issues in Interdisciplinary Studies, 33, 144-180.

Hendry, A., Hays, G., Challinor, K., \& Lynch, D. (2017). Undertaking Educational Research Following the Introduction, Implementation, Evolution, and Hybridization of Constructivist Instructional Models in an Australian PBL High School. Interdisciplinary Journal of Problem-Based Learning, 11(2), 7.

Henriksen, D. (2014). Full STEAM ahead: Creativity in excellent STEM teaching practices. The STEAM journal, 1(2), 15 . 
Honey, M., Pearson, G., \& Schweingruber, H. A. (Eds.). (2014). STEM integration in K-12 education: Status, prospects, and an agenda for research (p. 180). Washington, DC: National Academies Press.

Huri, N. H. D., \& Karpudewan, M. (2019). Evaluating the effectiveness of Integrated STEM-lab activities in improving secondary school students' understanding of electrolysis. Chemistry Education Research and Practice, 20(3), 495-508.

Inoa, R., Weltsek, G., \& Tabone, C. (2014). A Study on the Relationship between Theater Arts and Student Literacy and Mathematics Achievement. Journal for Learning through the Arts, $10(1)$, n1.

Jaeger, P. (2015). STEM, eSTEM, and the cybrarian: What every librarian should know. School Library Management, 161.

Kasza, P., \& Slater, T. F. (2017). A Survey of Best Practices and Key Learning Objectives for Successful Secondary School STEM Academy Settings. Contemporary Issues in Education Research, 10(1), 53-66.

Keane, L., \& Keane, M. (2016). STEAM by Design. Design and Technology Education, 21(1), 6182.

Kelley, T. (2010). Staking the Claim for the "T" in STEM. Journal of Technology Studies, 36(1), 211.

Kelley, T. R., \& Knowles, J. G. (2016). A conceptual framework for integrated STEM education. International Journal of STEM Education, 3(1), 11.

Klein, J. T. (2008). Evaluation of interdisciplinary and transdisciplinary research: a literature review. American journal of preventive medicine, 35(2), S116-S123.

Land, M. H. (2013). Full STEAM ahead: The benefits of integrating the arts into STEM. Procedia Computer Science, 2O, 547-552.

Le Grande, O. D. (2018). Chemistry as a creative science. Foundations of Chemistry, 2O(1), 3-13.

Leonardo, Z. (2004). Theme issue: Disciplinary knowledge and quality education: Editor's introduction. Educational Researcher, 33(5), 3-5.

Madden, M. E., Baxter, M., Beauchamp, H., Bouchard, K., Habermas, D., Huff, M., \& Plague, G. (2013). Rethinking STEM education: An interdisciplinary STEAM curriculum. Procedia Computer Science, 2O, 541-546.

Marinova, D., \& McGrath, N. (2004, February). A transdisciplinary approach to teaching and learning sustainability: A pedagogy for life. In Teaching and Learning Forum.

Martins Gomes, D., \& McCauley, V. (2021). Creativity in science: A dilemma for informal and formal education. Science Education.

McClam, S., \& Flores-Scott, E. M. (2012). Transdisciplinary teaching and research: what is possible in higher education?. Teaching in Higher Education, 17(3), 231-243.

Mergendoller, J. R., Maxwell, N. L., \& Bellisimo, Y. (2000). Comparing problem-based learning and traditional instruction in high school economics. The Journal of Educational Research, 93(6), 374-382.

Moher, D., Liberati, A., Tetzlaff, J., \& Altman, D. G. (2009). Preferred reporting items for systematic reviews and meta-analyses: the PRISMA statement. Annals of internal medicine, 151(4), 264-269.

Papacosta, P. (2007). Humanities \& Arts to the Rescue of Science. In Forum on Public Policy Online (Vol. 2007, No. 1, p. n1). Oxford Round Table. 406 West Florida Avenue, Urbana, IL 61801.

Park, J. Y., \& Son, J. B. (2010). Transitioning toward transdisciplinary learning in a multidisciplinary environment. International Journal of Pedagogies and Learning, 6(1), 82-93. 
Price Waterhouse Cooper Australia (2018). 21st century minds: Accelerator program. Retrieved from https://www.pwc.com.au/stem.html.

Rinne, L., Gregory, E., Yarmolinskaya, J., \& Hardiman, M. (2011). Why arts integration improves long-term retention of content. Mind, Brain, and Education, 5(2), 89-96.

Roehrig, G. H., Moore, T. J., Wang, H. H., \& Park, M. S. (2012). Is adding the E enough? Investigating the impact of K-12 engineering standards on the implementation of STEM integration. School Science and Mathematics, 112(1), 31-44.

Root-Bernstein, R. S. (2001). Music, creativity and scientific thinking. Leonardo, 34(1), 63-68.

Root-Bernstein, R., and Root-Bernstein M. (2011). Turning STEM into STREAM: Writing as an essential component of science education. The National Writing Project website, Retrieved from https://www.nwp.org/cs/public/print/resource/3522.

Rufo, D. (2013). STEAM with a capital A: Learning frenzy. The STEAM Journal, 1(1), 25.

Sanders, M. (2015). Integrative STEM education: A more robust explanation, Retrieved from https://www. iteea. org/File.aspx

Sanders, M. E. (2009). Stem, stem education, stemmania. The Technology Teacher, 20-26.

Savage, J. (2012). Moving beyond subject boundaries: Four case studies of cross-curricular pedagogy in secondary schools. International Journal of Educational Research, 55, 79-88.

Savery, J. R. (2015). Overview of problem-based learning: Definitions and distinctions. Essential readings in problem-based learning: Exploring and extending the legacy of Howard $S$. Barrows, 9, 5-15.

Schoenfeld, A. H. (2004). Multiple learning communities: students, teachers, instructional designers, and researchers. Journal of Curriculum Studies, 36(2), 237-255.

Scholz, R. W., Lang, D. J., Wiek, A., Walter, A. I., \& Stauffacher, M. (2006). Transdisciplinary case studies as a means of sustainability learning: Historical framework and theory. International Journal of Sustainability in Higher Education, 7(3), 226-251.

Schuchardt, A. M., \& Schunn, C. D. (2016). Modeling scientific processes with mathematics equations enhances student qualitative conceptual understanding and quantitative problem solving. Science Education, 100(2), 290-320.

Spelt, E. J., Biemans, H. J., Tobi, H., Luning, P. A., \& Mulder, M. (2009). Teaching and learning in interdisciplinary higher education: A systematic review. Educational Psychology Review, 21(4), 365.

Stubbs, E. A., \& Myers, B. E. (2016). Part of What We Do: Teacher Perceptions of STEM Integration. Journal of Agricultural Education, 57(3), 87-100.

Struyf, A., De Loof, H., Boeve-de Pauw, J., \& Van Petegem, P. (2019). Students' engagement in different STEM learning environments: integrated STEM education as promising practice?. International Journal of Science Education, 41(10), 1387-1407.

Taylor, P. C. (2016). Why is a STEAM curriculum perspective crucial to the 21st century?. Australian Council for Educational Research, 89-93.

Thomas, J. \& Williams, C. (2009). The history of specialized STEM schools and the formation and role of the NCSSSMST. Roeper Review, 32(1), 17-24.

Thomas, J. W. (2000). A review of research on project-based learning, California, United States of America, The Autodesk Foundation.

Vahey, P., Rafanan, K., Patton, C., Swan, K., van Hooft, M., Kratcoski, A., \& Stanford, T. (2012). A cross-disciplinary approach to teaching data literacy and proportionality. Educational Studies in Mathematics, 81(2), 179-205.

Wang, H. H., Moore, T. J., Roehrig, G. H., \& Park, M. S. (2011). STEM integration: Teacher perceptions and practice. Journal of Pre-College Engineering Education Research $(J-$ PEER), 1(2), 2. 
Webber, G., \& Miller, D. (2016). Progressive pedagogies and teacher education: A review of the literature. McGill Journal of Education/Revue des sciences de l'éducation de McGill, 51(3), 1061-1079.

Wells, J. (2011). International education, values and attitudes: A critical analysis of the International Baccalaureate (IB) Learner Profile. Journal of Research in International Education, 10(2), 174-188.

Yakman, G., \& Lee, H. (2012). Exploring the exemplary STEAM education in the US as a practical educational framework for Korea. Journal of the Korean Association for Science Education, 32(6), 1072-1086.

Yee-King, M., Grierson, M. \& d'Inverno, M. (2017). STEAM WORKS: Student coders experiment more and experimenters gain higher grades, Global Engineering Education Conference (EDUCON), 2017 IEEE, p. 359-366.

Yaki, A. A., Saat, R. M., Sathasivam, R. V., \& Zulnaidi, H. (2019). Enhancing Science Achievement Utilising an Integrated STEM Approach. Malaysian Journal of Learning and Instruction, 16(1), 181-205. 